\title{
El pontifical de Luis de Acuña y la iluminación de manuscritos en la Castilla de finales del siglo XV
}

\author{
Mercedes LÓPEZ-MAYÁN \\ Universidade de Santiago de Compostela \\ mercedes.lopez-mayan@usc.es
}

\begin{abstract}
RESUMEN
Entre los casi cincuenta pontificales medievales que se conservan en la antigua Corona de Castilla, uno de los ejemplares más destacados es el de Luis de Acuña, obispo de Burgos a finales del siglo XV. Nuestro objetivo es analizar el rico programa de miniaturas que presenta poniéndolo en relación con su texto, sus rasgos codicológicos y la personalidad de su comitente. En última instancia, mostramos cómo confluyen en él algunas de las características propias de la iluminación de manuscritos y, en general, de la actividad artística castellana de esta época, tales como el peso del estilo tardogótico, la imitación de grabados nórdicos o el mecenazgo de grandes aristócratas laicos y eclesiásticos.
\end{abstract}

Palabras clave: Pontifical, Burgos, Edad Media, Luis de Acuña, Iluminación, Estilo Tardogótico.

\begin{abstract}
Among the fifty medieval pontificals kept in the ancient kingdom of Castille, one of the most relevant is Luis de Acuña's copy. This pontifical was commissioned when he was bishop of Burgos at the end of the $\mathrm{XV}^{\text {th }}$ century. The objective of this paper is to analyze the sumptuous miniatures of this copy and to relate them with the text, the codicological features and the author's personality. In addition, we show that the manuscript presents some typical characteristics of the Castilian artistic activity at this time: the Late Gothic style, the imitation of Northern engravings or the sponsorship carried out by high dignitaries.
\end{abstract}

Keywords: Pontifical, Burgos, Middle Ages, Luis de Acuña, Illumination, Late Gothic Style.

Los pontificales eran, en el Medioevo, los libros litúrgicos específicos de los obispos y, por tanto, contenían las rúbricas y oraciones empleadas en aquellos ritos que solo los prelados podían celebrar; tal era el caso de la confirmación, las ordenaciones, la dedicación de iglesias, la bendición de abades y abadesas, la consagración de vírgenes, la sacralización de reyes y reinas, la expulsión y reconciliación de los penitentes el miércoles de ceniza y el Jueves Santo, la bendición de los santos óleos o la convocatoria de concilios ${ }^{1}$. Pero, además de su vocación utilitaria, con

1 Resulta muy complejo definir con exactitud lo que en la Edad Media se entendía por pontifical debido a la evolución de la liturgia contenida en este tipo de manuscritos y, sobre todo, a la inexistencia de unos límites precisos con otros libros litúrgicos. Para una aproximación sucinta al concepto de pontifical véanse V. LEROQUAIS, Les pontificaux manuscrits des bibliothèques publiques de France, vol. I, París, 1937, pp. IV y ss.; H. LECLERQ, "Pontifical”, Dictionnaire d'archéologie chrétienne et de liturgie, París, 1939, t. 14, cols. 1428-1445; C. RABEL, "Pontifical", Dictionnaire d'histoire de l'art du Moyen Âge occidental, París, 2009, 
frecuencia su cuidada factura material los convertía en instrumentos de ostentación del poder ideológico y económico de sus propietarios, ya fueran los propios obispos, los abades o, con frecuencia, los cabildos catedralicios ${ }^{2}$. Por ello, su estudio es fundamental para conocer las relaciones de poder, la liturgia y la producción y circulación de manuscritos en torno a las catedrales, centros de la vida religiosa, política, cultural y económica de la Castilla bajomedieval ${ }^{3}$.

Uno de los aspectos más interesantes que ofrecen los pontificales es el análisis de su ornamentación puesto que, a partir de la aparición de los primeros ciclos de iluminación en el siglo XIII, fue habitual la presencia de un programa iconográfico propio, generalmente en forma de iniciales historiadas que representan al obispo -y, en ocasiones, también al papa- llevando a cabo los diferentes ritos contenidos en el texto al que acompañan. Ello, unido a la irregularidad en la importancia de la decoración entre unos ejemplares y otros y a la diversidad en la selección de los motivos iluminados y en su disposición dentro de cada manuscrito, posibilita el análisis de las relaciones entre texto e imagen y la reflexión acerca de la función que las miniaturas desempeñaban en estos libros litúrgicos. Además, gracias al abundante número de pontificales que se conservan y a su dispersión, espacial y cronológica, por todo el Occidente medieval, están representados en ellos todos los estilos de iluminación europeos y sus relaciones ${ }^{4}$.

En el caso de la antigua Corona de Castilla, sus archivos y bibliotecas custodian actualmente unos cincuenta pontificales medievales de liturgia romana, de los cuales aproximadamente veintiséis están iluminados y, entre ellos, veinte presentan las características iniciales historiadas. Solo algunos ejemplares destacan por su profusa y lujosa decoración, generalmente relacionada con el mecenazgo de importantes obispos y arzobispos; uno de los más notables es el pontifical de Luis de Acuña, obispo de Burgos entre 1456 y $1495^{5}$. El valor de este manuscrito ya fue notado

pp. 754-755; y M. LÓPEZ-MAYÁN, "Liturgia y manuscritos en la Castilla medieval: algunos problemas metodológicos en el estudio de los pontificales", British Archaeological Reports (en prensa).

2 Una interesante reflexión sobre la propiedad y uso de los pontificales se contiene en J.B. LEBIGUE, "Chapelles livresques et ministres désignés. Les véritables destinataires des manuscrits de la liturgie pontificale”, Gazette du livre médiéval, 54 (2009), pp. 19-30.

3 Desde que M. Andrieu, C. Vogel y R. Elze realizaran las primeras ediciones críticas (M. ANDRIEU, Le Pontifical romain au Moyen Âge, Ciudad del Vaticano, 1938-1941; C. VOGEL y R. ELZE, Le Pontifical romano-germanique du dixième siècle, Ciudad del Vaticano, 1962-1972) han sido múltiples los trabajos elaborados sobre la liturgia, la materialidad, el uso o el significado de los pontificales, principalmente en Francia; sin embargo, los manuscritos que se conservan en las bibliotecas y archivos castellanos apenas han llamado la atención de los historiadores, con la excepción de algunos ejemplares especialmente lujosos. Su estudio global constituye el objeto de nuestra Tesis, "Liturgia y poder en la Edad Media. Estudio de los pontificales en el antiguo Reino de León y Castilla”, realizada con el apoyo del Programa de Formación de Profesorado Universitario del Ministerio de Educación.

4 Sobre estas cuestiones, véanse, a modo de introducción, V. LEROQUAIS, op. cit., 1937, pp. CXXIX y ss; y E. PALAZZO, L'Êveque et son image: l'illustration du pontifical au Moyen Âge, Turnhout, 1999.

5 Madrid, Biblioteca Nacional de España (BNE), ms. Vitr. 18-9 y microfilm no 7974. 
por Paul Durrieu en $1893^{6}$ y, desde entonces, ha llamado la atención de múltiples investigadores; sin embargo, con la excepción de las noticias, más o menos detalladas, incluidas en varios catálogos ${ }^{7}$, la mayoría de las referencias bibliográficas que hemos encontrado contienen únicamente alusiones puntuales al pontifical, utilizadas para ejemplificar o argumentar tal o cual cuestión, pero sin que en ninguna ocasión el manuscrito y, en lo que ahora más nos interesa, su iluminación, hayan sido objeto de un estudio global ${ }^{8}$. El objetivo de este artículo es, pues, analizar el programa de miniaturas de este manuscrito poniéndolo en relación con su texto, sus rasgos codicológicos y la personalidad de su comitente y, paralelamente, situarlo en la encrucijada de diversos estilos, influencias y manifestaciones que caracterizaron la rica actividad artística castellana, y particularmente burgalesa, en el ocaso de la Edad Media.

El pontifical de Luis de Acuña está realizado en vitela de gran calidad y consta de 342 folios, cuyas dimensiones son de 320x215 mm. Con la excepción de los doce primeros, presentan foliación coetánea en cifras romanas y se organizan en 44 cuadernos, mayoritariamente cuaterniones y dotados de reclamos sin decoración. El texto se dispone a una columna de $222 \times 132 \mathrm{~mm}$, con 25 líneas y pautado a mina de plomo, y está escrito en gótica libraria castellana, muy cuidada y regular y con intervención de varias manos, incluyendo las que, a partir del siglo XVI, realizaron pequeñas adiciones marginales. Lamentablemente, no conserva la encuadernación original y, en su lugar, presenta una cubierta neoclásica, con tapas de papelón y tafilete rojo, decoración de filetes dorados y guardas de papel verjurado con filigrana de flor de lis.

Desde el punto de vista de su contenido, el manuscrito pertenece a la última de las familias litúrgicas identificadas por Michel Andrieu, la de Guillermo Durando, con sus tres partes características, dedicadas, respectivamente, a las ordenaciones y bendiciones de personas, a la consagración y bendición de diversos bienes litúrgicos, muebles e inmuebles, y, finalmente, a las celebraciones características de la

6 P. DURRIEU, Manuscrits d'Espagne remarquables par leurs peintures et par la beauté de leur execution, París, 1893 , p. 54.

7 J. DOMÍNGUEZ BORDONA, Exposición de códices miniados españoles: catálogo, Madrid, 1929, p. 66, n 106; y Manuscritos con pinturas. Notas para un inventario de los conservados en colecciones públicas y particulares de España, vol. I, Madrid, 1933, nº 922, fig. 313; H. ANGLÉS y J. SUBIRÁ, Catálogo Musical de la Biblioteca Nacional de Madrid, vol. I, Barcelona, 1946, pp. 119-120, nº 49; J. JANINI y J. SERRANO, Manuscritos Litúrgicos de la Biblioteca Nacional, Madrid, 1969, pp. 238-245, n 194 y láms. 19 y 20; Reyes y Mecenas. Los Reyes Católicos, Maximiliano I y los inicios de la Casa de Austria en España, Madrid, 1992, pp. 363-364, n 96; J. VALDEÓN BARUQUE et alii (coords.), El Testamento de Adán, Valladolid-Lisboa, 1994, pp. 153-155, n 30; y R. KAY, Pontificalia. A repertory of latin manuscript pontificals and benedictionals, Kansas, 2007, nº 433. En línea: <http://hdl.handle.net/1808/4406> [Consulta: 22 de septiembre de 2009].

8 Hemos omitido la referencia a todos los artículos y libros en que se cita el pontifical de Luis de Acuña para evitar una lista excesivamente prolija y que, por lo sintético de muchas referencias, no es relevante para el tema que aquí tratamos. No obstante, muchos de estos trabajos serán mencionados a lo largo de las páginas que siguen con lo que el lector dispondrá, en última instancia, de la información bibliográfica más relevante sobre este manuscrito. 
Semana Santa y a otros rituales y ceremonias diocesanas ${ }^{9}$. El pontifical está completo, es decir, contiene todos los ordines propios de esta familia y, además, en los folios preliminares incorpora las bendiciones episcopales para el ciclo del año (ff. Ir-VIIr) ${ }^{10}$, el prefacio e índice característicos de la versión de Durando (ff. IXr-Xv) y el orden y canon completo de la misa pontifical (ff. XIIr-34r).

El análisis codicológico y textual del manuscrito es fundamental porque arroja abundante luz sobre la fecha, lugar y circunstancias en que el códice fue fabricado y, por tanto, permite situar la iluminación en su contexto correcto. Sabemos, así, que el pontifical fue realizado por encargo de Luis de Acuña y Osorio, miembro de la alta nobleza castellana, obispo de Burgos, como ya se señaló, entre 1456 y 1495 y destacada personalidad de su época, tanto desde el punto de vista político -fue un firme partidario de Enrique IV y, posteriormente, de Isabel la Católica-, como en el campo del arte y la cultura, pues, bajo su mecenazgo, se acometieron muchas de las empresas que convirtieron a Burgos en un foco artístico excepcional ${ }^{11}$. La identificación del prelado es clara porque en los folios $22 \mathrm{v}$ y $23 \mathrm{r}$, en el margen inferior de las cenefas que rodean ambas páginas, se representan sus armas: las cinco llagas de Cristo sobre campo de oro, reminiscencia, por otro lado, de la devoción franciscana del obispo, que también se deja traslucir en la presencia de frailes de esta Orden entre los marginalia de los folios XIIr, 22v y $41 \mathrm{v}$ (fig. 3) ${ }^{12}$.

Como se verá más adelante, todo ello es clave en el análisis de la función y significado que la lujosa ornamentación del códice posee y, además, permite establecer un arco cronológico coherente con el tipo de escritura y el estilo de la iluminación. Con algunas precisiones derivadas de la inspiración de algunas miniaturas en grabados de Martin Schongauer y del maestro I.A.M. de Zwolle -que se comentarán posteriormente-, es posible situar la confección del manuscrito hacia los años ochenta del siglo XV, coincidiendo con el pontificado de Inocencio VIII (1434-1492), a quien muy posiblemente alude la rúbrica contenida en el ordo De examinatione, ordinatione et consecratione episcopi: Vis beato Petro apostolo cui a Deo data est potestas ligandi atque solvendi eiusque vicario, sanctissimo patri

9 M. ANDRIEU, op. cit., 1938-1941, t. 3, Le Pontifical de Guillaume Durand, Ciudad del Vaticano, 1940. Véase la transcripción de los incipits y explicits de los ordines de este pontifical en J. JANINI y J. SERRANO, op. cit., 1969, pp. 238-245.

${ }^{10}$ Identificamos con cifras romanas los folios que no tienen numeración original en el manuscrito; para los demás, del 1 al 330, seguimos la foliación del códice, pero, por razones de comodidad, utilizamos números arábigos.

11 Sobre Luis de Acuña véanse E. FLÓREZ, España Sagrada, Teatro Geográphico-Histórico de la Iglesia de España, tomo XXVI: Contiene el estado antiguo de las Iglesias de Auca, de Valpuesta y de Burgos, Madrid, 1771, pp. 403-412; N. LÓPEZ MARTÍNEZ, "Don Luis de Acuña, el cabildo de Burgos y la Reforma (1456-1495)", Burgense, 2 (1961), pp. 185-317; y B. BARTOLOMÉ MARTÍNEZ (coord.), Iglesias de Burgos, Osma-Soria y Santander, Madrid, 2004, pp. 118-121.

12 Sobre la influencia y el papel que la Orden franciscana desempeñó en la realidad castellana de finales del siglo XV, véase J.M. NIETO SORIA, "Franciscanos y franciscanismo en la política y en la Corte de la Castilla Trastámara (1369-1475)”, Anuario de Estudios Medievales, 20 (1990), pp. 109-131. 
domino I., summo pontifici, eiusque successoribus et vicariis romanis pontificibus atque sancta romane ecclesie michi ministro... fidem... exhibere? (f. 69r).

Finalmente, del análisis textual también se infiere que el manuscrito no solo perteneció al obispo de Burgos, sino que, además, se realizó para ser usado en la propia catedral burgalesa. Así lo indican claramente la presencia de sancti Adelelme (o Lesmes), patrón local, en las letanías (f. 12r) $)^{13}$, y la alusión a la ecclesie burgensi en el interrogatorio que el obispo debía hacer al abad dentro del ordo De confirmatione vel consecratione et benedictione regularis abbatis: Vis huic sancta matri ecclesie burgensi michique eiusdem episcopo meisque successoribus fidem subiectionem obedienciam et reverenciam devote ac fideliter perpetuo exhibere? (f. 91r).

Como señalamos anteriormente, este manuscrito es, de los pontificales conservados en Castilla, uno de los ejemplares más notables en

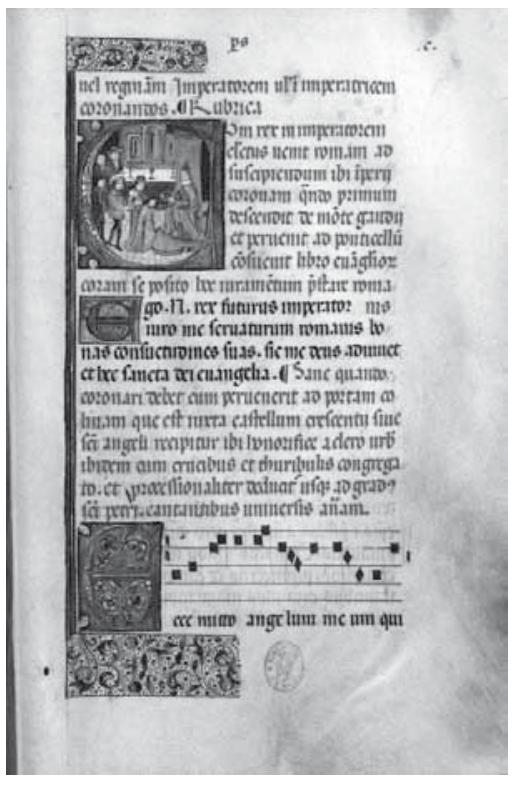

Fig. 1. Coronación del emperador. Pontifical de Luis de Acuña, Burgos, ca. 1480 (Madrid, (C) BNE, ms. Vitr. 18-9, f. 100r). cuanto a la riqueza de su iluminación. Qué elementos la componen y cómo se pueden integrar en el proceso de creación artística que se dio en la Península Ibérica al final de la Edad Media son las cuestiones que abordaremos a continuación.

El pontifical de Luis de Acuña contiene tres miniaturas a página completa y una enorme cantidad de iniciales iluminadas, de las cuales la mayoría se decoran con motivos vegetales y florales -especialmente en los folios preliminares, que contienen el canon de la misa- y cincuenta son historiadas, es decir, el cuerpo de las letras alberga escenas relacionadas con la liturgia episcopal. Todas ellas, además, se prolongan en dos líneas verticales (la exterior dorada y la interior azul o magenta con toques en blanco) que ocupan todo el alto de la caja de escritura y rematan, en cabeza y pie, en dos cenefas horizontales que, enmarcadas por líneas de oro, se decoran con pequeñas flores azules, hojas y palmas doradas y puntos azules y dorados (fig. 1). Este mismo tipo de orla encuadra las tres páginas completamente iluminadas, con la peculiaridad de que, en estos casos, entre la profusa vegetación emergen diversas figuras humanas -incluyendo varios franciscanos, un cardenal, ángeles entonando salmos o tocando instrumentos o un cazador persiguiendo a su presa- $y$ animales -pavos reales, un mono vestido con manto, diversos pájaros, una mari-

13 Sobre la figura de San Lesmes y su significación en el contexto burgalés, véase S. LÓPEZ SANTIDRIÁN (ed.), San Lesmes en su tiempo, Burgos, 1997. 


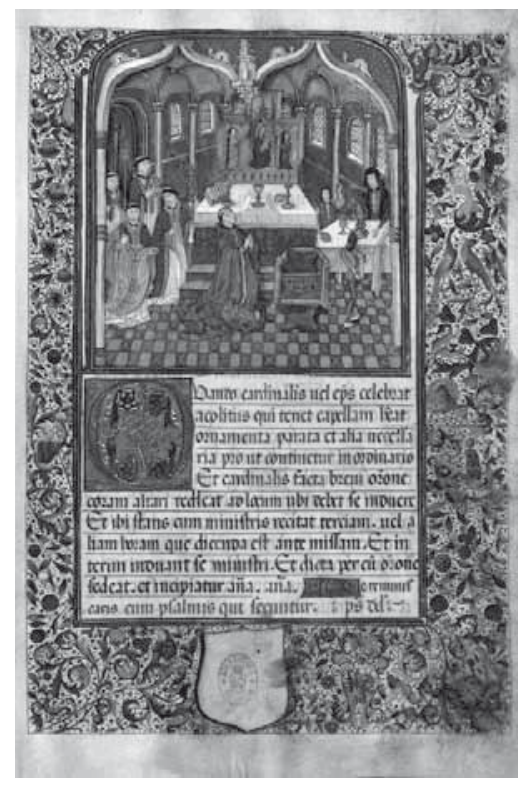

Fig. 2. Preparación para la misa solemne. Pontifical de Luis de Acuña (Madrid, () BNE, ms. Vitr. 18-19, f. XIIr).

posa o un perro tocando una cítara- (figs. 2-4). Se trata, además, de un tipo de decoración muy próxima a las borduras de los manuscritos debidos al taller de Willem Vrelant y realizados en los Países Bajos franceses entre 1470 y $1490^{14}$.

A ello habría que añadir la decoración secundaria dispersa a lo largo de todo el manuscrito y común en los códices de esta cronología: iniciales tipo champie sin decoración de antenas ni caídos, mayúsculas con filigrana al comienzo de los textos con notación musical, remates de renglón tipo champie en el índice y en las letanías de los folios 47r-49 y 106v-107r, remates de renglón geométricos y en tinta roja, cruces de bendición champie y calderones azules. En conjunto, todos estos elementos, trazados con paleta completa -aunque predominan tonos fuertes como el azul oscuro o el magenta- y con notable presencia del oro, otorgan al pontifical la apariencia de códice lujoso y extremadamente valioso, encargado por un comitente, Luis de Acuña, que no escatimó recursos a la hora de proveerse del libro necesario para sus obligaciones litúrgicas.

La primera miniatura destacada se encuentra en el folio XIIr, coincidiendo con el inicio del orden de la misa pontifical e ilustra el texto correspondiente, en el que se indica el modo en que el celebrante, cardenal u obispo, debe prepararse antes de la ceremonia. En la imagen, éste reza, arrodillado, ante el altar sobre el que están dispuestos varios objetos litúrgicos y un retablo-tríptico, mientras a su espalda cuatro presbíteros, ricamente ataviados, sostienen las vestiduras que el prelado va a ponerse -la mitra, la casulla y el báculo-; en el lado opuesto, tres laicos, engalanados para la ocasión, preparan, sobre una mesa, los instrumentos que se necesitarán a lo largo de la misa -aguamanil, palangana, píxide, etc.- (fig. 2).

14 Entre los paralelos más destacados, se encuentran las borduras del manuscrito sobre Les Chroniques d'Angleterre - particularmente, del volumen iluminado por el Maestro del Evangeliario de Tournai (París, Bibliotheque Nationale de France, ms. français 79) - o del Libro de Horas romano conservado en Baltimore, Walters Art Gallery, ms. W 10.195. Véanse sendas imágenes en I. HANS-COLLAS y P. SCHANDEL, Manuscrits enluminés des anciens Pays-Bas méridionaux. Manuscrits de Louis de Bruges, París, 2009, lám. XXIII; y A. STONES y J. STEYAERT, Medieval illumination, glass and sculpture in Minnesota Collections, Minnesota, 1978, p. 70, respectivamente. Para una sucinta referencia al origen y labor de Willem Vrelant y su taller, véase T. KREN, "Willem Vrelant", Illuminating the Renaissance: the Triumph of Flemish Manuscripts Painting in Europe, Los Ángeles, 2003, pp. 117-119. 
Las otras dos miniaturas principales del manuscrito se localizan en los folios $22 \mathrm{v}$ y $23 \mathrm{r}$ y forman un ciclo de imágenes asociadas al significado eucarístico del texto al que acompañan, la oración del Te igitur, en el comienzo preciso del canon de la misa, que introduce la rememoración de la Pasión de Cristo como preludio de su conversión en Majestad y Juez salvífico. Por un lado, el Calvario, desarrollo máximo e independiente de los crucificados que, desde muy antiguo, se representaron al inicio de este rezo aprovechando la forma crucífera de la letra $\mathrm{T}^{15}$ : sobre el paisaje de una ciudad amurallada, posiblemente Jerusalén, Cristo en la cruz ocupa el centro de la imagen; a su derecha, tres personajes aparecen nimbados: la Virgen, San Juan y una de las santas mujeres, que, según el relato evangélico, presenciaron la crucifixión ${ }^{16}$; y a su izquierda, equilibrando la composición pero contraponiéndose al santo grupo, tres gentiles que conversan entre sí y de los que solo es iden-

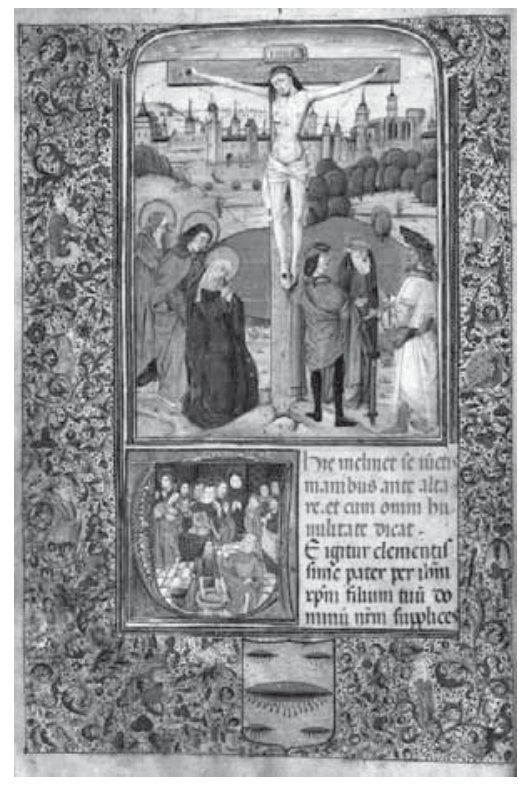

Fig. 3. Calvario y Última Cena. Pontifical de Luis de Acuña (Madrid, (C) BNE, ms. Vitr. 18-19, f. 22v). tificable el que viste túnica amarilla y porta una espada: se trata, muy probablemente, del centurión que, según las Escrituras, reconoció, tras la muerte de Cristo, que "verdaderamente éste era el Hijo de Dios"17. Bajo esta imagen, la letra " $\mathrm{T}$ " del Te igitur alberga la escena del lavatorio de pies, previo a la Última Cena y preámbulo de la Pasión que culminaría con la crucifixión de Jesús (fig. 3$)^{18}$.

Por otro lado, en el folio 23r se representa a Cristo en majestad: sentado en un trono lujosamente decorado, eleva su mano derecha para bendecir mientras sostiene, con la izquierda, el orbe y el cetro, símbolos, junto a la doble corona cerrada, de la autoridad imperial. La riqueza de sus vestiduras y el modo, casi visionario, en que dos ángeles lo muestran al espectador al descorrer sendos cortinajes ratifican

15 J. YARZA LUACES, "Iconografía de la crucifixión en la miniatura española. Siglos X al XII", Archivo Español de Arte, 47 (1974), pp. 13-37. Sobre el origen y evolución de la iluminación del Te igitur véase también O. PÄCHT, La miniatura medieval. Una introducción, Madrid, 1987 (Munich, 1984), pp. 40-44.

16 Mt 27, 56; Mc 15, 40-41 y Jn 19, 25-27.

17 Mt 27, 54; Mc 15, 39 y Lc 23, 47. Apuntamos, asimismo, la posibilidad de que estos gentiles representen, como es habitual en el arte cristiano, las tres edades del hombre: el de la izquierda es imberbe, el centurión porta barba y pelo castaño y, en el centro, el más anciano tiene una larga barba blanca.

18 Nótese que de los doce apóstoles solo uno no está tocado con el nimbo de santidad, Judas Iscariote, el traidor, que cubre su cabeza con un turbante azul. 
la intención de aludir a él como Cristo-rey o Rex regum, tal y como se recoge en los Evangelios ${ }^{19}$. En el mismo sentido ha de interpretarse la inscripción en oro que decora el doselete grana del trono, "Altitudo divitiarum sapiencie et ciencie Dei", primer verso del canto a la sabiduría y la grandeza divinas contenido en Romanos 11, 33 (fig. 4).

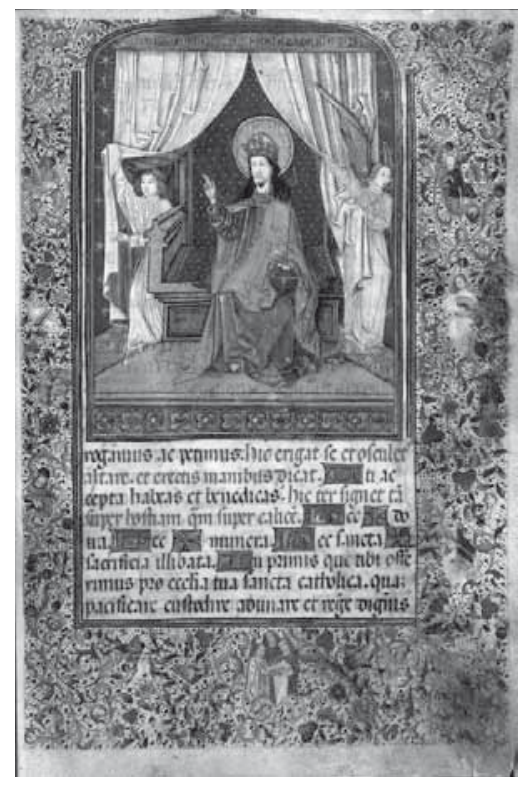

Fig. 4. Cristo en majestad. Pontifical de Luis de Acuña (Madrid, () BNE, ms. Vitr. 18-19, f. 23r).

La representación y asociación de ambas imágenes al comienzo del canon eucarístico no es original ni exclusiva de este manuscrito, sino que la encontramos en otros ejemplares conservados en Castilla, como el llamado Pontifical Hispalense, realizado hacia 1390 para uso de Juan de Villacreces, obispo de Calahorra y la Calzada (1382-1394) ${ }^{20}$. Tampoco resulta extraña la presencia en los pontificales del motivo iconográfico del Te igitur, más propio de sacramentarios y misales puesto que es habitual que, como ocurre en este caso, incluyan el canon de la misa, bien al principio, bien en el ordo del Jueves Santo.

Mayor especificidad poseen las cincuenta iniciales historiadas que pueblan el manuscrito puesto que su iconografía sí es exclusiva de los libros pontificales al representar, como se ha indicado, al obispo $-y$, a veces, al papa- desempeñando sus diversos cometidos litúrgicos ${ }^{21}$. Del mismo modo, aunque su número y selección varía enormemente de unos códices a otros, su orden -sobre todo, en los pontificales de la Curia romana del siglo XIII y de G. Durando- suele estar muy tipificado ${ }^{22}$. Al igual que ocurre en el pontifical de Luis de Acuña y siguiendo la disposición de los ordines, suelen comenzar por las ordenaciones, consagración del emperador, bendición de abad y monjes y consagración

19 Lc 1, 32-33. T. Burollet ha señalado, además, que los dos ángeles descorriendo las cortinas podrían ser una reminiscencia de algún rito bizantino de coronación imperial (T. BUROLLET, Martin Schongauer, maître de la gravure rhénane vers 1450-1491, París, 1991, p. 136).

20 Sevilla, Biblioteca Capitular y Colombina (BCC), ms. BB 149-3, ff. 296v-297. Véanse también J. GUERRERO LOVILLO, "El Pontifical Hispalense”, Archivo Hispalense, 39 (1958), pp. 125-139, y F. MANZARI, La miniatura ad Avignone al tempo dei papi (1310-1410), Módena, 2006, pp. 10, 15, 181, 249252, 257, 260, 264, 352, 353 y figs. 126-128.

${ }^{21}$ Para una visión global del nacimiento y evolución de la iluminación de los pontificales véase E. PALAZZO, op. cit., 1999, especialmente pp. 111-181.

22 Entre los ejemplares castellanos, se observa la misma disposición de las iniciales historiadas, aunque en número muy desigual, en el pontifical de Tui, Archivo Histórico Diocesano (AHD), ms. 3 y en el de Toledo, Biblioteca de Castilla La Mancha (BCLM), ms. 167. 
de vírgenes y viudas, para continuar con la dedicación de la iglesia, la consagración del altar o la bendición de vestimentas y objetos litúrgicos, y finalizar con la bendición del óleo del Jueves Santo, la comunión de los enfermos, la reconciliación de los penitentes o la celebración de concilios $^{23}$. Asimismo, es habitual -y el manuscrito que nos ocupa tampoco es una excepción- que la iconografía de los pontificales se base en las rúbricas que acompaña y sirva, por lo tanto, para ilustrar la ejecución de los correspondientes ritos; es decir, la coherencia entre texto e imagen es un rasgo destacable en este tipo de libros, lo que no significa necesariamente que las miniaturas ofrezcan una representación verosímil de cómo se desarrollaban en la realidad todos esos rituales (fig. 2).

Desde el punto de vista de su estilo y de las influencias que en él confluyen, el pontifical de Luis de Acuña se inserta plenamente en el contexto histórico-artístico vivido en Castilla y, particularmente, en el foco burgalés entre 1440 y 1500, aproximadamente ${ }^{24}$. La existencia de intensos contactos comerciales con las principales plazas mercantiles del Norte de Europa -Amberes, Brujas y Bruselas, notoriamente ${ }^{25}$, unida al estrechamiento de las relaciones políticas -que culminarían en la integración de Flandes en la Monarquía Hispánica- ${ }^{26}$, favoreció la llegada de algunos artistas germanos y flamencos y, sobre todo, la penetración de los gustos, inquietudes y objetos artísticos nacidos en esas tierras ${ }^{27}$; gustos y objetos que, además, respondían a la demanda de una nobleza castellana de nuevo cuño, la trastamarista o enriqueña, que, frente a la debilidad de la autoridad regia, vio en el arte un medio de reafirmación y ostentación de su poder. De ahí que nos encontremos, como en el caso evidente de este manuscrito, ante un arte promovido por reyes, magnates eclesiásticos y grandes nobles e imbuido, por tanto, de una especial sensibilidad cortesana.

Este complejo proceso, expuesto aquí de manera muy sintética, tuvo en Burgos un foco excepcional. Económicamente, la función de esta ciudad en el conjunto

23 Por razones de espacio, omitimos la descripción detallada de los motivos representados en cada una de las cincuenta iniciales. Remitimos al lector que desee tener una visión sucinta al respecto a la noticia sobre el manuscrito ofrecida por J. JANINI y J. SERRANO, op. cit., 1969, pp. 238-245.

24 S.A. ORDAX, "El foco artístico burgalés", La Ciudad de Burgos. Actas del Congreso de Historia de Burgos en el MC Aniversario de la Fundación de la Ciudad, Madrid, 1985, pp. 845-859.

25 J. MARÉCHAL, "La colonie espagnole de Bruges du XIV e au XVI" siècle", Revue du Nord, 35 (1953), pp. 5-40.

26 W. THOMAS y E. STOLS, "La integración de Flandes en la Monarquía Hispánica”, Encuentros en Flandes. Relaciones e intercambios hispanoflamencos a inicios de la Edad Moderna, Lovaina, 2000, pp. $1-73$.

27 Para una reflexión general sobre la penetración e influencia del arte de los Países Bajos en Castilla y, en particular, sobre la (problemática) cuestión de la llegada de artistas flamencos a territorio castellano, véanse J. YARZA LUACES, "El arte de los Países Bajos en la España de los Reyes Católicos", Reyes y Mecenas. Los Reyes Católicos, Maximiliano I y los inicios de la Casa de Austria en España (Catálogo de Exposición, Toledo, 12 de marzo-31 de mayo, 1992), Madrid, 1992, pp. 133-150; y Los Reyes Católicos. Paisaje artístico de una monarquía, Madrid, 1993, especialmente pp. 369-388. 
de Castilla era muy pujante pues los pasos de la Mesta hacia La Rioja transitaban por su territorio y, sobre todo, porque sus mercaderes controlaban el grueso del comercio con el Norte de Europa, especialmente desde la creación del Consulado de la Universidad de Mercaderes de Burgos en 1494 por los Reyes Católicos ${ }^{28}$. Políticamente, los Condestables de Castilla, en quienes recaía el mando supremo del ejército, estaban vinculados a esta urbe desde que en 1473 Enrique IV le concediera el título a Pedro Fernández de Velasco. Su pujanza económica era compartida, asimismo, por los destacados obispos aristócratas y grandes mecenas del arte que presidieron el solio burgalés durante estos años: Alonso de Cartagena (1435-1456) y el propio Luis de Acuña. A instancias de todos ellos, se llevaron a cabo gran cantidad de ambiciosos proyectos artísticos que modificaron la fisonomía de la catedral y de la ciudad de Burgos con la introducción y predominio del gusto flamenco ${ }^{29}$.

Las influencias recibidas de este modo desde el Norte de Europa confluyeron con las inercias de los artistas castellanos y dieron lugar al llamado estilo tardogótico, que caracterizó la creación artística de Castilla al final de la Edad Media ${ }^{30}$. Este proceso también afectó a la producción de códices ${ }^{31} \mathrm{y}$, especialmente, a los más lujosos, cuyo consumo por parte de las élites sociales se incrementó de manera notable a medida que la imprenta fue divulgando nuevos soportes escritos y acentuó, más si cabe, las connotaciones de ostentación y lujo que los manuscritos poseían.

Dos rasgos del estilo tardogótico son especialmente destacados en el pontifical de Luis de Acuña, además de la ya comentada reinterpretación de las cenefas florales características del taller de W. Vrelant: el cuidado particular de los fondos y la inspiración en grabados noreuropeos. En lo que se refiere al primer aspecto, se observa que el iluminador ha puesto gran atención en plasmar detalladamente los espacios, tanto interiores como exteriores, en los que se sitúan los rituales que decoran las ini-

28 S.A. ORDAX, op. cit., 1985, p. 851. De hecho, J. Yarza ha señalado que "casi fue lugar común de la literatura castellana del siglo XV identificar comerciante burgalés con hombre afortunado que ha obtenido grandes ganancias con sus negocios en Brujas". J. YARZA LUACES, op. cit., 1992, p. 134.

29 Véanse H. KARGE, La catedral de Burgos y la arquitectura del siglo XIII en Francia y en España, Valladolid, 1995 (Berlín, 1989); F. PEREDA y A. RODRÍGUEZ G. DE CEBALLOS, “Coeli enarrant gloriam dei. Arquitectura, iconografía y liturgia en la capilla de los Condestables de la catedral de Burgos", Annali di architettura, 9 (1997), pp. 17-34; y J.C. RUIZ SOUZA, "La planta centralizada en la Castilla bajomedieval: entre la tradición martirial y la qubba islámica. Un nuevo capítulo de particularismo hispano", Anuario del Departamento de Historia y Teoría del Arte, 13 (2001), pp. 9-36.

30 Empleamos el término tardogótico en lugar de hispano-flamenco, denominación frecuente en la historiografía pero que oculta las importantes aportaciones que, junto a los Países Bajos, protagonizaron Borgoña, Francia, Alemania o Italia en la actividad artística de estos años (D. HEIM, "Tardogótico internacional o hispano-flamenco: las corrientes artísticas del Alto Rhin en el foco toledano", El arte foráneo en España: presencia e influencia, Madrid, 2005, pp. 37-38). Sobre la pintura de este periodo en Castilla, véase M.P. SILVA MAROTO, La pintura hispanoflamenca castellana: Burgos y Palencia, obras en tabla y sarga, 2 vols., Valladolid, 1999.

31 Véase, entre otros, F. VILLASEÑOR SEBASTIÁN, "Préstamos e influencias extranjeras en la miniatura hispanoflamenca castellana”, El arte foráneo en España: presencia e influencia, Madrid, 2005, pp. 227235 . 
ciales historiadas y las miniaturas de los folios XIIr, 22v y 23r (figs. 1-4). A través de la representación de unas arquitecturas ligeras y de un mobiliario litúrgico minucioso, el artista resalta el significado de las escenas localizadas en el primer plano y crea un efecto de teatralidad, en cierta medida consustancial a la propia liturgia pero ausente en otros pontificales iluminados en estilos romano o aviñonés, en los que los fondos de las miniaturas son planos y monocromos $^{32}$. Sin embargo, como en el caso de otros pintores tardogóticos, se perciben algunas dificultades en la consecución de la perspectiva y cierta desproporción entre las figuras y el marco arquitectónico que las acoge. Ello es consecuencia de la concentración del interés no en éste, sino en los personajes, rasgo típico de la iconografía de los pontificales, cuyo objetivo es recalcar la relación jerárquica entre las figuras y las posiciones y gestos que muestren la superioridad episcopal dentro del cuerpo eclesiástico.

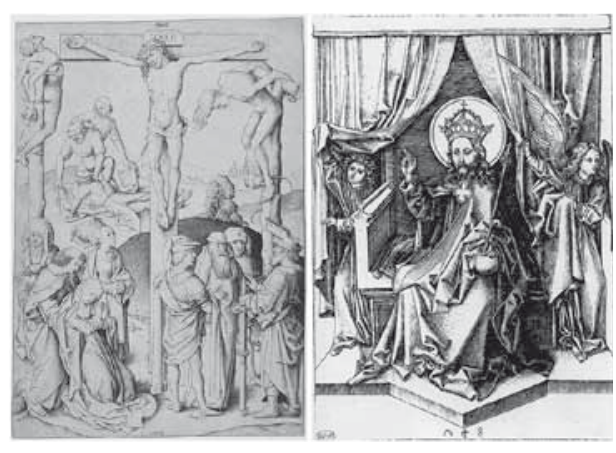

Fig. 5. Grabados de I.A.M. de Zwolle (ca. 14401504), Calvario; y Martin Schongauer (ca. 14501491), Cristo en majestad.

En cuanto al segundo aspecto, diversos autores han notado cómo las miniaturas de los folios $22 \mathrm{v}$ y $23 \mathrm{r}$ (figs. 3-4) están inspiradas en los diseños de algunos de los grabadores más destacados de este período. La imagen del Calvario interpreta, con bastante fidelidad, uno de los trabajos del maestro I.A.M. de Zwolle (ca. 1440-1504), si bien se observan algunas diferencias, no solo en la menor plasticidad y concisión en el dibujo del iluminador de nuestro manuscrito, sino también en la ausencia de ciertos personajes del grabado, como los dos ladrones, los romanos que se juegan a suertes la ropa de Jesús, una de las santas mujeres y el cuarto personaje que aparece en el grupo de la derecha (fig. $5)^{33}$. Este mismo diseño se adoptó como base para la ejecución de múltiples pinturas sobre este tema, aunque con mayores variaciones en las figuras representadas, sus rasgos o el paisaje; tal es el caso de la tabla atribuida al círculo de Alonso de Sedano y conservada en el Museo Diocesano de Palma de Mallorca ${ }^{34}$ o de la Crucifixión realizada por Rodrigo de Osona para la iglesia de San Nicolás (Valencia) ${ }^{35}$.

Por su parte, la imagen de Cristo en majestad es una fiel imitación del grabado realizado por Martin Schongauer (ca. 1450-1491) hacia 1480, si bien se incorpora algún

32 A modo de ejemplo, éste es el caso de pontificales como los de la Real Biblioteca de El Escorial (RBME), ms. O.I.7, Sevilla, BCC, mss. 56-1-11 y 56-1-28, Toledo, BCLM, ms. 167 o Tui, AHD, ms. 3.

33 M.P. SILVA MAROTO, "Influencia de los grabados nórdicos en la pintura hispanoflamenca", Archivo Español de Arte, 243 (1988), p. 276.

34 Ibidem, p. 276 y fig. 8.

35 Véase su reproducción en J. YARZA LUACES, op. cit., 1993, p. 341. 
elemento novedoso -como la inscripción en el dosel del trono, ya comentada-y, una vez más, la destreza del iluminador castellano es menor, como se percibe claramente en el rostro de Cristo ${ }^{36}$ (fig. 5). No conocemos ninguna otra miniatura en Castilla que se inspire en este mismo grabado; sin embargo, Lynette M. F. Bosch ha señalado la existencia de otros tres manuscritos que contienen ilustraciones inspiradas en trabajos de Schongauer, de los cuales uno de ellos, la Regla de la Cofradía de Santa María de la Creaçon de Burgos, fue también realizado, en 1494, bajo los auspicios del obispo Luis de Acuña, como se comentará más adelante ${ }^{37}$. Y, con carácter general, han sido muchos los estudios que han revelado la enorme influencia que los grabados noreuropeos ejercieron en la pintura tardogótica, particularmente en Aragón ${ }^{38}$, y en artistas de la talla de Fernando Gallego ${ }^{39}$ o Rodrigo Alemán ${ }^{40}$.

¿Conocía el iluminador del pontifical de Luis de Acuña los grabados de I.A.M. de Zwolle y de Martin Schongauer? ¿Cómo llegó a interpretar los trabajos de los dos artistas nórdicos y a integrarlos en el programa iconográfico del manuscrito burgalés? Al margen de la, en ocasiones, pretendida presencia de Schongauer en suelo castellano ${ }^{41}$, conviene tener en cuenta, por un lado, que la mayoría de estos grabados estaban consagrados a temas religiosos, funcionaban como imágenes de devoción y, en cuanto tales, eran objeto de un comercio, incluso a larga distancia ${ }^{42}$. Su circulación fue, además, más rápida y amplia y menos costosa gracias a las ver-

36 Esta similitud ha sido detectada por múltiples investigadores; entre ellos, destacamos a D. ANGULO ÍÑIGUEZ, "Martin Schongauer y algunas miniaturas castellanas", Arte Español, 7 (1924-1925), pp. 177178; y “Gallego y Schongauer”, Archivo Español de Arte y Arqueología, 6 (1930), pp. 74-75; J. JANINI y J. SERRANO, op. cit., 1969, p. 238; L.M.F. BOSCH, “A terminus ante quem for two of Martin Schongauer's Crucifixions”, The Art Bulletin, 64 (1982), p. 632; y J. CAMPBELL HUTCHISON, Early German Artists: Martin Schongauer, Ludwig Schongauer and copyists ('The Illustrated Bartsch', 8/1), Nueva York, 1996, pp. 111-113. De entre todos ellos es particularmente interesante el trabajo de L.M.F. Bosch ya que la autora utiliza el pontifical de Luis de Acuña, además de otros manuscritos con miniaturas inspiradas en grabados de Schongauer, para datar, aproximadamente, algunos de los trabajos de este artista, que no consignó la fecha en ninguna de sus obras.

37 Los otros dos ejemplos son un Libro de Horas, posiblemente procedente de Burgos y encargado por un miembro de la familia Zúñiga (RBME, ms. Vit. 10 iii-e-2) y el misal del cardenal Pedro González de Mendoza (Toledo, Biblioteca Capitular, ms. Res. 5) (L.M.F. BOSCH, op. cit., 1982).

38 M.C. LACARRA DUCAY, "Huella de Martin Schongauer en los primitivos aragoneses", Archivo Español de Arte, 207 (1979), pp. 347-349; e "Influencia de Schongauer en los primitivos aragoneses", Boletín del Museo e Instituto Camón Aznar, 17 (1984), pp. 15-39.

39 D. ANGULO ÍÑIGUEZ, op. cit., 1930, pp. 74-75; J.R. NIETO GONZÁLEZ y D. RODRIGUES (coords.), Fernando Gallego (1440-1507), Salamanca, 2004; y W. DOTSETH, B.C. ANDERSON y M.A. ROGLÁN (eds.), Fernando Gallego and his workshop: The Altarpiece from Ciudad Rodrigo. Paintings from the Collection of the University of Arizona Museum of Art, Londres, 2008.

40 D. HEIM, op. cit., p. 38 y ss.

${ }^{41}$ Se ha especulado sobre la posibilidad de que, dentro del viaje que Schongauer realizó como culminación de su aprendizaje, hubiera estado en España; así lo indicarían ciertos tipos moros presentes en sus grabados o la representación de la batalla de Clavijo encabezada por el apóstol Santiago. Sin embargo, no existe ninguna prueba documental que avale tal hipótesis (L.M.F. BOSCH, op. cit., 1982, p. 632; y T. BUROLLET, op. cit., 1991, p. 70).

42 T. BUROLLET, op. cit., 1991, p. 84. 
siones impresas: la llegada de la imprenta a la Península Ibérica, y particularmente a Burgos en $1485^{43}$, multiplicó la disponibilidad de unos modelos, que, además, desde un punto de vista plástico e iconográfico, ofrecían formas de expresión más libres y nuevos temas, y se adecuaban perfectamente al gusto de sus consumidores. Para los Países Bajos se conoce el caso de dos grabadores, Pieter van Middembliic y Martin van Axele, que fueron miembros de la Guilda de Iluminadores de Brujas en la segunda mitad del siglo XV, lo que demostraría que el uso de estampas por parte de los miniaturistas no era extraño ${ }^{44}$.

Por otro lado, tampoco se debe perder de vista que las imágenes plasmadas en muchos de estos grabados, así como sobre otros soportes, fueron a menudo recogidas en libros de modelos o muestras que los iluminadores y artistas empleaban como referencias o fuentes de inspiración. Aunque apenas se han conservado ejemplos -ninguno, por lo menos, para el caso de Castilla-, estos repertorios abren otra vía en la explicación del proceso creativo al negar la necesidad de que el artista trabajara siempre con el original de su modelo delante ${ }^{45}$.

Empleara directamente los grabados o sus versiones, lo que queda claro, en todo caso, es que el iluminador de nuestro pontifical no se limitó a copiar los diseños nórdicos, sino que introdujo elementos propios y, de entre los motivos que le llegaron a través de manuscritos importados, de otras obras de arte tardogóticas y/o de los libros de modelos, seleccionó aquéllos que más le interesaron y los adaptó a sus capacidades, al gusto de su cliente y a las inercias creativas presentes en la miniatura castellana tardogótica ${ }^{46}$.

${ }^{43}$ S.A. ORDAX, op. cit., 1985, p. 851.

${ }^{44}$ F. VILLASEÑOR SEBASTIÁN, op. cit., 2005, pp. 231-232; y "La estampa, difusora de motivos iconográficos profanos al final de la Edad Media: el caso castellano", Goya, 313/314 (2006), pp. 211-220, acerca de la utilización de grabados alemanes como fuentes de inspiración de algunos motivos iluminados por el miniaturista Juan de Carrión, activo en Ávila y Segovia entre 1470 y 1479.

${ }^{45}$ Sobre la compleja cuestión de la originalidad y la copia en el arte medieval, véanse las reflexiones contenidas en R.W. SCHELLER, Exemplum. Model-Book Drawings and the Practice of Artistic Transmission in the Middle Ages (ca. 900-ca. 1470), Amsterdam, 1995; S. MORALEJO ÁLVAREZ, "Modelo, copia y originalidad, en el marco de las relaciones artísticas hispano-francesas (siglos XI-XIII)", Patrimonio artístico de Galicia y otros estudios. Homenaje al profesor Dr. Serafín Moralejo Álvarez, Santiago de Compostela, 2004, pp. 75-96, en p. 93; E. PAGELA, "Vedere, copiare, interpretare: artista e circulazione di modelli nell' ambito ecclesiastico", Arti e storia nel Medioevo, Milán, 2004, vol. I, pp. 473-512; F. CRIVELLO, "L'immagine ripetuta: filiazione e creazione nell'arte del Medioevo", Arti e storia nel Medioevo, Milán, 2004, pp. 567-592; y F. AVRIL, "Les copies à répétition. À propos de la circulation et de la dissémination des modèles", Tributes to Jonathan J. G. Alexander: the making and meaning of illuminated medieval and Renaissance manuscripts, Londres, 2006, pp. 127-140. Recientemente, A. Ritz-Guilbert ha identificado un libro de modelos realizado a partir de un manuscrito y empleado, posteriormente, en la iluminación de otros códices, mostrando, sobre la base de evidencias concretas, el funcionamiento de este proceso (A. RITZ-GUILBERT, Des drôleries gothiques au bestiaire de Pisanello. Le Bréviaire de Marie de Savoie, París, 2010, especialmente pp. 247-284).

46 Para un acercamiento a las vías de penetración e influencia de los manuscritos iluminados foráneos -notablemente, los flamencos- en la miniatura de la Península Ibérica, véase J. DOCAMPO CAPILLA, "La importación de manuscritos iluminados y su influencia en la miniatura de la Península Ibérica: 1470-1570", La miniatura medieval en la Península Ibérica, Murcia, 2007, pp. 255-311. 
Solo falta dilucidar una última cuestión: ¿cuál era la función desempeñada por estas miniaturas en el manuscrito? Una de las misiones de la iluminación, general, por otra parte, en el mundo de los códices medievales, es la de articular el texto: a través de la jerarquía de iniciales historiadas, iluminadas y con filigrana, en distintos tamaños, el contenido del pontifical queda claramente estructurado en diversos capítulos u ordines con sus subapartados correspondientes, lo que facilitaba el manejo de un libro concebido con una finalidad práctica. Asimismo, dado el carácter ritual de la iconografía y su coherencia con las rúbricas que acompaña, resulta obvio que tras las miniaturas subyace un deseo de ilustración del contenido y naturaleza del manuscrito, insertándolo en la tradición de los pontificales iluminados ${ }^{47}$.

Pero, sobre todo, la decoración de este códice posee una dimensión ideológica fundamental encaminada a destacar la labor y personalidad del obispo que lo encargó. Al igual que ocurre, en efecto, con otros pontificales ricamente iluminados ${ }^{48}$, el que ahora estudiamos está vinculado a una ilustre personalidad eclesiástica, Luis de Acuña, que actuó como un gran aristócrata y pretendió consolidar su poder imponiéndose a otros nobles, ganándose el favor regio y desarrollando importantes programas de reforma eclesiástica ${ }^{49}$. En definitiva, se trata de un claro ejemplo de los llamados "manuscritos de aparato", especialmente abundantes al final de la Edad Media, en asociación con la poderosa nobleza castellana y en el momento en que, como ya se comentó, la introducción de la imprenta acentuó su valor. Ahora bien, esta dimensión de ostentación solo se puede ponderar adecuadamente si contextualizamos este ejemplar en la importante labor de mecenazgo artístico y cultural que Luis de Acuña llevó a cabo en la sede burgalesa. Bajo sus auspicios continuaron trabajando los destacados artistas nórdicos llegados a Burgos durante el episcopado anterior, Juan de Colonia y su hijo, Simón, y a ellos les encargó la realización del gran cimborrio de la catedral y la capilla de los Condestables, de cuya decoración escultórica se ocupó, en un principio, Gil de Siloé; su hijo, Diego de Siloé, sería, a partir de 1519 -ya fallecido el obispo-, el responsable del monumento funerario del propio prelado, situado en la capilla de Santa Ana o de la Concepción.

Además, como otros grandes señores de la época, Luis de Acuña fue un destacado bibliófilo ${ }^{50}$ : poseyó una biblioteca compuesta por 363 volúmenes, según el

47 E. PALAZZO, op. cit., 1999.

48 Tal es el caso de los dos pontificales realizados para Alonso Carrillo, arzobispo de Toledo (14461482): Madrid, BNE, ms. Vitr. 18-6 y Toledo, Biblioteca Capitular de Toledo, ms. 56.24. O del pontifical de Juan de Villacreces, obispo de Calahorra y la Calzada (1382-1394): Sevilla, BCC, ms. BB 149-3.

49 Sobre la actuación política de Luis de Acuña durante el conflicto entre Isabel y Juana la Beltraneja y en los inicios del reinado de los Católicos, véase B. BARTOLOMÉ MARTÍNEZ (coord.), op. cit., 2004, p. 120. Sobre las iniciativas reformadoras del prelado, véanse Ibidem, pp. 119-120; y N. LÓPEZ MARTÍNEZ, op. cit., 1961.

50 Para una aproximación general al uso y consumo de libros en la España medieval, con especial atención a los últimos siglos, véase, I. BECEIRO PITA, Libros, lectores y bibliotecas en la España medieval, Murcia, 2007. 
inventario realizado un año después de su muerte, en $1496^{51}$, y posiblemente su pontifical perteneció a un grupo mayor de manuscritos litúrgicos auspiciados por él mismo ${ }^{52}$. Dos indicios, al menos, parecen apuntar en esa dirección. Por un lado, el códice que contenía la Regla de la Cofradía de Santa María de la Creaçon de Burgos, dada por Luis de Acuña en 1494, del que únicamente se conservan unos folios, decorados con las armas del prelado y un Calvario y una Epifanía inspirados en sendos grabados de Schongauer, como ya se señaló ${ }^{53}$. Y, por otro lado, el manuscrito de la Cofradía del Santísimo y de Santiago -fundada en Burgos hacia 1338 y en apogeo en tiempos de nuestro prelado-, puesto que el trabajo de uno de sus iluminadores, el miniaturista de 1501, ha sido relacionado por Joaquín Yarza con el estilo de las ilustraciones del pontifical, derivándose de ello la posibilidad de que el mismo artista haya trabajado en más de un manuscrito en tiempos de Luis de Acuña ${ }^{54}$.

Así pues, queda claro que este códice no solo es un ejemplo excepcional de la miniatura castellana del final del Medioevo, sino que, además, a través de un estudio global y contextualizado, es posible insertarlo plenamente en las directrices que marcaron la iluminación de manuscritos y, más allá, la creación artística en Castilla en el inicio de la época moderna. $81-110$.

${ }^{2}$ N. LÓPEZ MARTíNEZ, “La biblioteca de D. Luis de Acuña en 1496”, Hispania, 20 (1960), pp.

52 Era muy habitual que los obispos y arzobispos más poderosos encargaran varios manuscritos litúrgicos, ricamente iluminados en un estilo similar e identificados con sus armas. Tal es el caso del cardenal Pedro González de Mendoza, arzobispo de Toledo (1482-1495), de quien se conocen, al menos, un misal, un pasionario, un breviario y dos libros de coro. Véanse, entre otros trabajos, L.M.F. BOSCH, Art, liturgy and legend in renaissance Toledo: the Mendoza and the Iglesia Primada, Pennsylvania, 2000; y Reyes y Mecenas... pp. 306-324 y 366-367.

53 Burgos, Archivo Capitular, ms. 12. Sobre este manuscrito, véanse J. DOMÍNGUEZ BORDONA, op. cit., 1929, p. 210 y lám. 63; D. MANSILLA REOYO, Catálogo de los Códices de la Catedral de Burgos, Madrid, 1952, pp. 88-89, nº 12 y lám. VII; T. BUROLLET, op. cit., 1991, p. 115; y J. CAMPBELL HUTCHISON, op. cit., 1996, p. 98 . Véase la reproducción de uno de estos folios en F. PALOMERO ARAGÓN et alii, La Catedral de Burgos. Una vanguardia artística medieval, Madrid, 2001, p. 219.

54 J. YARZA LUACES, "La ilustración en el códice de la Cofradía del Santísimo y de Santiago, en Burgos", Locus Amoenus, 1 (1995), pp. 7-32. 